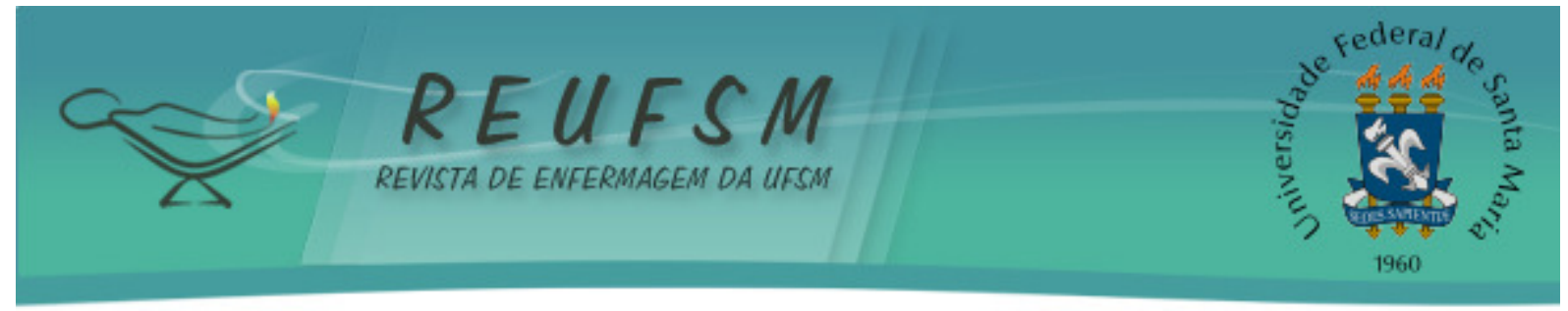

ARTIGO ORIGINAL

\title{
A DECISÃO DE AMAMENTAR DURANTE A ADOLESCÊNCIA: UM ESTUDO NA PERSPECTIVA CULTURAL
}

THE DECISION TO BREASTFEED DURING ADOLESCENCE:A STUDY IN CULTURAL PERSPECTIVE

LA DECISIÓN DE AMAMANTAR DURANTE LA ADOLESCENCIA: UN ESTUDIO EN PERSPECTIVA CULTURAL

\author{
Luiza Cremonese ${ }^{1}$ \\ Laís Antunes Wilhelm ${ }^{2}$ \\ Lisie Alende Prates ${ }^{3}$ \\ Andrêssa Batista Possati ${ }^{4}$ \\ Juliane Scarton ${ }^{5}$ \\ Lúcia Beatriz Ressel ${ }^{6}$
}

Doi: $10.5902 / 2179769219248$

RESUMO: Objetivo: conhecer como foi culturalmente construída a decisão de amamentar, durante a adolescência, por um grupo de mulheres. Método: estudo de campo, descritivo, qualitativo, desenvolvido com oito mulheres. Os dados foram coletados por meio de entrevista semiestruturada, e utilizou-se a análise de conteúdo temática da proposta operativa. Resultados:a decisão de amamentar associou-se à herança cultural, transmitida entre as gerações e caracterizada pelas influências familiares, as experiências prévias de outras mulheres e o conhecimento sobre os benefícios da amamentação para a criança. Ainda envolveu as orientações fornecidas pelos profissionais de saúde, e as captadas nos meios de comunicação. Conclusão: a decisão de amamentar constitui um processo de aprendizagem, construído no contexto em que as mulheres estão inseridas. Assim, a contribuição deste estudo perpassa a ampliação do olhar sobre a amamentação, reconhecendo-a como uma prática influenciada pela cultura.

Descritores: Saúde da mulher; Adolescente; Aleitamento materno; Cultura; Enfermagem.

ABSTRACT: Aim: to know how the decision to breastfeed was culturally constructed during adolescence, by a group of women. Method: field study, descriptive, qualitative, developed with eight women. The data were collected through semi-structured interview, and analyzed under the thematic content analysis of operative proposal. Results: the decision to breastfeeding is connected to cultural heritage, transmitted through generations and characterized by family influences, the previous experiences of other women and the knowledge about the benefits of breastfeeding for the child. The guidance provided by health professionals and captured in the media is also involved. Conclusion: the decision to breastfeed is a learning process, built in the context in which women are included. Thus, the contribution of this study is to look at enlargement on breastfeeding, recognizing it as a practice influenced by culture.

Descriptors:Women's health; Adolescent; Breast Feeding; Culture; Nursing.

\footnotetext{
${ }^{1}$ Enfermeira. Mestranda do Programa de Pós-graduação em Enfermagem da Universidade Federal de Santa Maria (PPGEnf/UFSM). Bolsista CAPES. Santa Maria, RS, Brasil. E-mail: lu_cremonese@hotmail.com

${ }^{2}$ Enfermeira. Doutoranda do PPGEnf/UFSM. Bolsista CAPES. Santa Maria, RS, Brasil. E-mail: laiswilhelm@gmail.com

3 Enfermeira. Doutoranda do PPGEnf/UFSM. Santa Maria, RS, Brasil. E-mail: lisiealende@hotmail.com

${ }^{4}$ Enfermeira. Mestranda do PPGEnf/UFSM. Santa Maria, RS, Brasil. E-mail: dessa_possati@hotmail.com

5 Enfermeira. Doutoranda do Programa de Pós-graduação em Enfermagem da Universidade Federal de Rio Grande (PPGEnf/FURG). Santa Maria, RS, Brasil. E-mail: juliscarton10@hotmail.com

${ }^{6}$ Enfermeira. Doutora. Professora Associada do Departamento de Enfermagem da UFSM. Santa Maria, RS, Brasil. E-mail: lbressel208@yahoo.com.br
} 


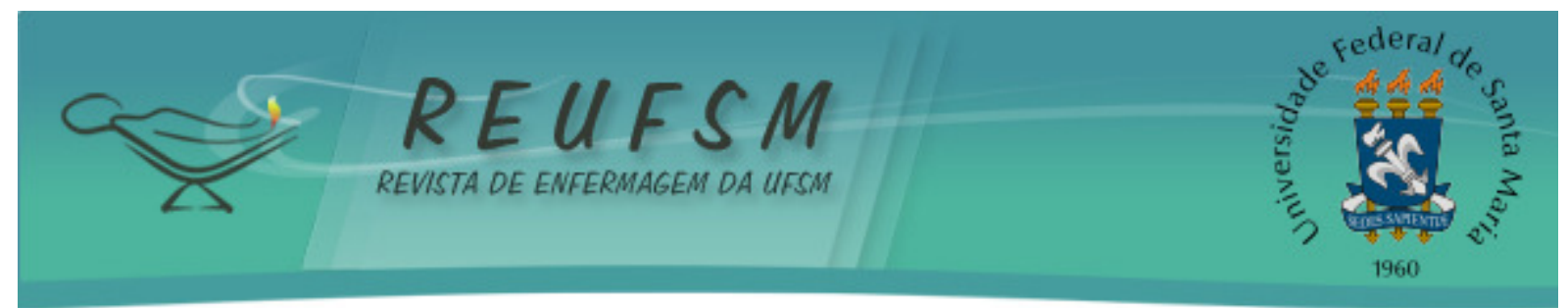

RESUMEN: Objetivo: conocer cómo fue culturalmente construida la decisión de amamantar en la adolescencia, en un grupo de mujeres. Método: estudio de campo, descriptivo, cualitativo, desarrollado con ocho mujeres. Los datos fueron recogidos a través de entrevista semiestructurada, y analizados por análisis temático de contenido de la propuesta operativa. Resultados: la decisión de amamantar asociase a la herencia cultural transmitida entre las generaciones y caracterizada por influencias familiares, las experiencias anteriores de otras mujeres y el conocimiento acerca de los beneficios de la lactancia materna para el niño. Sigue involucrada con la orientación proporcionada por profesionales de la salud y capturadas en los medios de comunicación. Conclusión: la decisión de amamantar es un proceso de aprendizaje, construido en el contexto en que están incluídas las mujeres. La contribución de este estudio fue ampliar la discusión sobre la lactancia materna, reconociéndola como una práctica influenciada por la cultura.

Descriptores: Salud de la mujer; Adolescente; Lactancia Materna; Cultura; Enfermería.

\section{INTRODUÇÃO}

A amamentação é entendida como um processo biológico, social e cultural, que envolve uma estratégia de vínculo e afeto entre mãe e filho e, ao mesmo tempo, um meio de proteção e nutrição para a criança. No ato de amamentar, estão implicados condicionantes apreendidos e disseminados no contexto cultural em que as pessoas estão inseridas. ${ }^{1}$ Nesse sentido, reconhece-se que a cultura é capaz de influenciar as percepções, crenças e práticas de cuidados sobre a amamentação.

No ambiente doméstico, a decisão de amamentar é influenciada pela história familiar das mulheres, ou seja, conforme a vivência da amamentação na família. Neste sentido, presume-se que este contexto poderá lhes proporcionar experiências positivas relacionadas com a amamentação. ${ }^{2}$

Portanto, considera-se que as percepções e os significados atribuídos ao processo de amamentar vão ao encontro das experiências compartilhadas, mas também vividas. Ao mesmo tempo, pondera-se que a amamentação é concebida como um comportamento cultural, ${ }^{3}$ imerso no contexto social, que é continuamente apreendido e ensinado entre as mulheres de diferentes gerações.

Por representar um processo cultural, a amamentação pode ser cercada por mitos e crenças herdadas dentro do contexto familiar. Associado a isso, quando a amamentação é vivenciada durante uma fase específica do ciclo vital como, por exemplo, a adolescência, esta pode assumir diferentes contrastes para a mulher adolescente, a qual pode requerer atenção diferenciada e estruturada do profissional de saúde. ${ }^{2}$

A vivência da amamentação durante a adolescência, pode representar um processo complexo, se forem consideradas as próprias características desta fase, caracterizada por um período de transição e marcada por inúmeras modificações. Frente a este contexto repleto de novas demandas, responsabilidades e experiências, algumas puérperas adolescentes tendem a não apresentar uma boa adesão à amamentação e maior probabilidade de desmame precoce. ${ }^{4}$

A pesquisa demonstrou que as adolescentes tendem a diminuir a amamentação conforme o bebê vai crescendo. Neste estudo, $60 \%$ das adolescentes amamentavam seus filhos no primeiro mês, porém esse percentual reduziu-se a $10 \%$ no terceiro mês. Ainda, no segundo mês $26,3 \%$ das jovens referiram ter introduzido alimentação complementar à dieta da criança. ${ }^{5} \mathrm{Em}$ contrapartida, outras adolescentes podem se apresentar como protagonistas nesse processo, demonstrando habilidades para cuidar de seu filho e também, terem boa adesão à amamentação. 


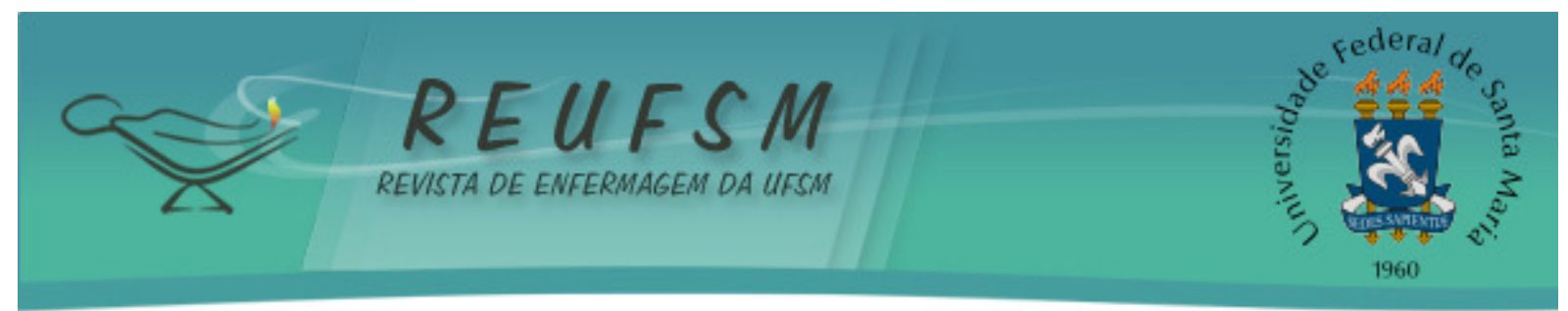

Em reforço a este ideal, a vivência precoce do processo gravídico-puerperal não pode ser resumida somente a impactos negativos. ${ }^{6}$ Portanto, reconhece-se e se justifica a importância de conhecer como foi culturalmente construída a decisão de amamentar por mulheres, durante a adolescência, a fim de fornecer subsídios aos profissionais de saúde para que estes possam desenvolver ações de saúde específicas, voltadas para este público. Além disso, possam oferecer um cuidado baseado nas necessidades de saúde dessas mulheres, respeitando o desejo de amamentar e de dar continuidade a esta prática.

Compreende-se que o cuidado voltado à mulher durante o processo de amamentação, seja ela adolescente ou não, precisa ultrapassar a dimensão biológica, balizando-se, também, nas condições econômicas, sociais e culturais presentes no contexto de vida de cada mulher. A atenção integral à saúde da mulher adolescente compreende o cuidado, a partir do conhecimento de cada contexto cultural, respeitando costumes, crenças, singularidades e a capacidade desta em ser responsável por suas escolhas. $^{7}$

O conhecimento da cultura, na qual as pessoas estão inseridas, e a compreensão frente às suas escolhas, são atitudes essenciais ao profissional de saúde. Por meio destes, é possível conhecer e identificar os padrões culturais que estimulam tais ações e condutas, conforme suas visões de mundo, valores, saberes e práticas. ${ }^{8}$

Se faz necessário o respeito e a valorização do sistema cultural em que estão inseridas as mulheres adolescentes, bem como o entendimento da própria adolescência como um processo construído historicamente e condicionado pelas particularidades de cada contexto sociocultural. ${ }^{3}$ No campo das pesquisas científicas, a cultura é apontada como um aspecto fundamental na atuação dos profissionais de saúde, contribuindo com a sua compreensão no cenário de cuidado dos indivíduos e, consequentemente, permitindo auxiliar na prática assistencial. ${ }^{9}$

Frente ao exposto, o presente estudo teve como questão de pesquisa: como se construiu culturalmente a decisão de amamentar em mulheres, durante a sua adolescência? $O$ objetivo desta pesquisa foi conhecer como foi culturalmente construída a decisão de amamentar, durante a adolescência, por um grupo de mulheres.

\section{MÉTODO}

Para alcançar o objetivo proposto, realizou-se um estudo de campo, de caráter descritivo, com abordagem qualitativa. 0 cenário para realização da pesquisa foi composto por quatro Unidades de Saúde, em um município do interior do Rio Grande do Sul, Brasil.

A seleção dos campos de estudo foi realizada por meio de sorteio e o número de participantes foi delimitado por saturação de dados, ${ }^{10}$ totalizando oito mulheres. Os critérios de inclusão abrangeram as mulheres que estavam amamentando e eram adolescentes, bem como, aquelas que não eram adolescentes, mas que haviam amamentado durante a adolescência. Logo, o estudo também abrangeu tanto as vivências atuais de adolescentes, como as rememoradas por mulheres adultas, durante a sua adolescência. Além disso, reforça-se que foram incluídas somente as mulheres que possuíam vínculo com as Unidades de Saúde, nas quais se realizou a pesquisa.

Ao contatar as mulheres que buscaram as Unidades de Saúde, atentou-se para o período puerperal que estas estavam vivenciando, durante o período de coleta de dados. Excluiu-se da pesquisa as mulheres que ainda estavam no período puerperal tardio, pois se considerou que este representava um período curto de vivência do processo de amamentação, além de apresentar características muito específicas, que não consistiam no foco do estudo. 


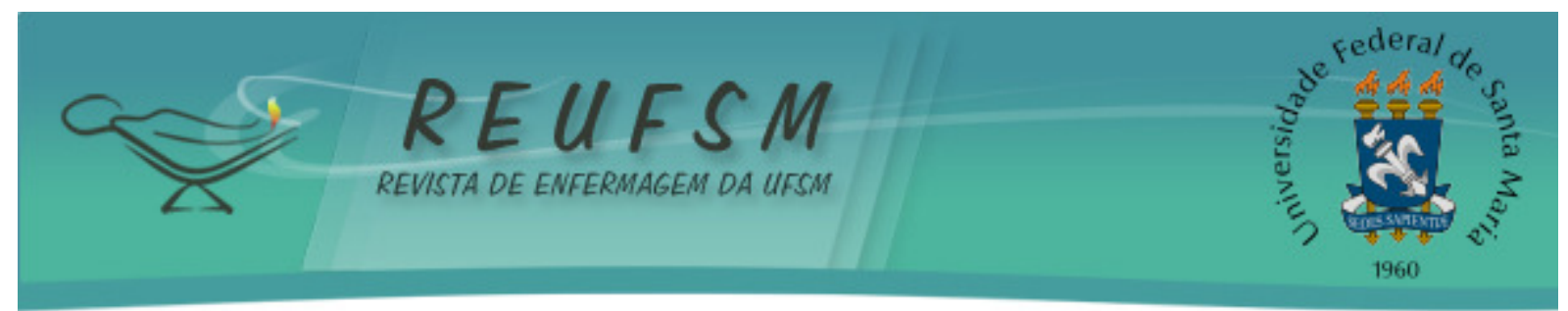

O contato com as participantes foi realizado nos dias em que elas compareceram nas Unidades, de forma intencional. Como instrumento para a obtenção dos dados, adotouse a entrevista semiestruturada. Os dados obtidos durante as entrevistas, foram audiogravados, com a autorização das entrevistadas, e após, transcritos para análise e interpretação. Utilizou-se o sistema alfa numérico para identificação das mulheres participantes da pesquisa, com a letra " $M$ " e numeração, conforme a ordem das entrevistas.

A análise dos dados fundamentou-se na análise de conteúdo temática da proposta operativa, ${ }^{11}$ caracterizada por dois níveis operacionais. 0 primeiro nível operacional envolveu a fase exploratória, enquanto que o segundo, a fase interpretativa.

Os preceitos da Resolução $n^{\circ}$. 466/12 do Conselho Nacional de Saúde, que dispõe sobre diretrizes e normas que regulamentam a pesquisa envolvendo a participação de seres humanos, foram assegurados e valorizados durante todo o estudo. A pesquisa foi aprovada pelo Comitê de Ética em Pesquisa, sob o número do parecer 760.735 e número do Certificado de Apresentação para Apreciação Ética (CAAE) 33679014.9.0000.5346. Após a aprovação desta instância, procedeu-se a coleta de dados, desenvolvida entre os meses de setembro e outubro de 2014.

\section{RESULTADOS E DISCUSSÃO}

Os resultados da pesquisa incluem, primeiramente, a caracterização das participantes por meio da descrição de seus dados de identificação. A faixa etária das entrevistadas variou entre 17 e 39 anos. Com relação ao grau de instrução, uma havia concluído o ensino médio, e a outra o ensino fundamental, duas apresentavam ensino médio incompleto, e quatro possuíam ensino fundamental incompleto.

Seis delas não trabalhavam e duas trabalhavam com carteira assinada. Quanto ao número de filhos, quatro tinham somente um filho e as outras, possuíam mais. Sete mulheres moravam com seus maridos e uma com sua mãe. Em relação ao estado civil, cinco se declararam solteiras e três, casadas.

Todas as mulheres participaram de, no mínimo, seis consultas de pré-natal. Todas amamentaram. Contudo, três amamentaram exclusivamente até os seis meses de vida da criança, as demais complementaram a amamentação com outros líquidos e/ou alimentos. Sete mulheres amamentaram por um período superior a seis meses e uma amamentou por um período mais curto.

Com o processo de análise dos dados, construiu-se o núcleo temático que envolve a vivência da amamentação por mulheres durante a adolescência. Este foi denominado de "Saberes e significados da amamentação para mulheres durante a adolescência na perspectiva cultural" e abarca, entre outros aspectos, a construção da decisão de amamentar pelas participantes.

Este núcleo temático também compreende alguns elementos relacionados com o contexto cultural das mulheres entrevistadas, destacando a influência exercida pela família, os profissionais de saúde e a sociedade frente à decisão de amamentar. Assim, as mulheres relataram o contexto e os atores envolvidos na construção destas decisões, como se percebe nas falas, a seguir.

Antes de amamentar, eu já sabia que o leite da mãe previne várias doenças. Sabia que fazia bem para a criança e para mim [...] Minha mãe que me falava isso, falava do jeito que tinha que pegar $o$ bebê. É que ela teve seis filhos, tinha experiência, né? (M1) 


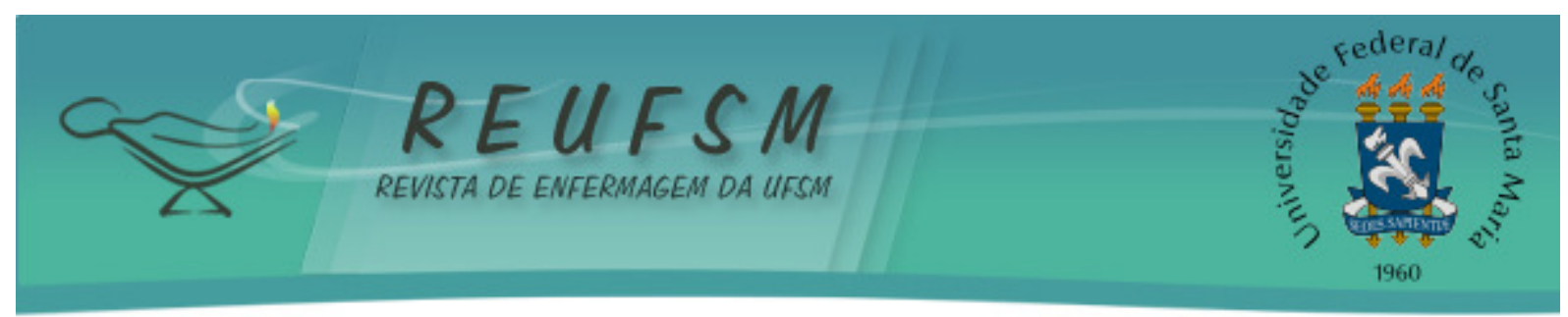

Eu fui bem orientada durante o pré-natal e participei também do grupo de gestante e aprendi com as outras mulheres, porque as que tinham mais experiência iam passando as coisas para as outras com menos experiência. (M5)

As enfermeiras do posto [...] falaram que era bem importante eu amamentar, pelo menos até os seis meses para a criança ficar bem saudável, mas que se quisesse continuar depois podia também, até os dois anos. E, hoje em dia, com todos esses problemas que têm nos leites, a gente sabe que é bem melhor dar o leite da gente, que a gente sabe que está tendo segurança, né? (M7)

Eu lia nas revistas e perguntava para a mãe [...] e ela ia me passando o conhecimento dela. (M8)

Considerando a amamentação um comportamento sócio e culturalmente aprendido, que depende de um processo de endoculturação, ${ }^{3}$ pondera-se que o fato de ter sido amamentada ou ter tido contato com alguém que tenha amamentado, gerou atitudes positivas e influenciou a decisão de amamentar ${ }^{12}$. Ademais, cabe salientar a importância dos profissionais de saúde nesse processo, em organizar o grupo de gestantes, o que proporciona troca de experiência e conhecimento. Desse modo, infere-se que as mulheres identificam as experiências vividas por outras mulheres como influências positivas, que trazem implicações para a sua decisão em amamentar. ${ }^{13}$

Ressalta-se, assim, a importância de valorizar e respeitar os conhecimentos construídos e repassados culturalmente no universo familiar das mulheres, pois estes podem refletir na adesão e na manutenção da amamentação. 0 conceito de cultura emerge, nessa direção, como um legado que os membros de um grupo transmitem entre as gerações. ${ }^{14}$

Uma pesquisa ${ }^{3}$ desenvolvida com adolescentes corrobora com os achados deste estudo, pois reforça a influência desempenhada pela família na adesão da amamentação. Os autores ${ }^{3}$ também destacam que a prática de amamentar sofre a interferência de fatores culturais e sociais transmitidos entre as gerações.

Outra pesquisa ainda reforça que, no ambiente familiar, as adolescentes são acolhidas e recebem apoio para organizar as atividades domésticas e o cuidado com o bebê. ${ }^{15}$ Logo, percebe-se a importância do profissional de saúde valorizar este espaço familiar e incluir esses indivíduos no cuidado.

0 exercício da maternidade, especialmente a amamentação, tende a ser um período de compartilhamento de experiências e de troca entre as mulheres mais experientes, que desenvolveram essa prática anteriormente, em conjunto com as mais jovens e inexperientes, que ainda não possuem habilidade. ${ }^{13} \mathrm{~A}$ amamentação apresenta-se, assim, como uma prática atrelada a determinantes sociais e culturais, presentes no processo de socialização das mulheres. ${ }^{16}$

Ademais, por se tratar de adolescentes, é preciso considerar que o processo de amamentação pode ser ainda mais complexo. Tornar-se mãe, durante a adolescência, implica em muitas adaptações e reajustes para o desenvolvimento da capacidade de cuidar de uma criança. Para isso, a adolescente necessita de apoio e suporte de seu meio relacional, o que muitas vezes não ocorre devido, principalmente, a não aceitação da família. ${ }^{2}$

Reforça-se que nenhuma das entrevistadas sinalizou a ausência de apoio ou suporte familiar. Ao contrário, elas destacaram as orientações fornecidas e principalmente o 


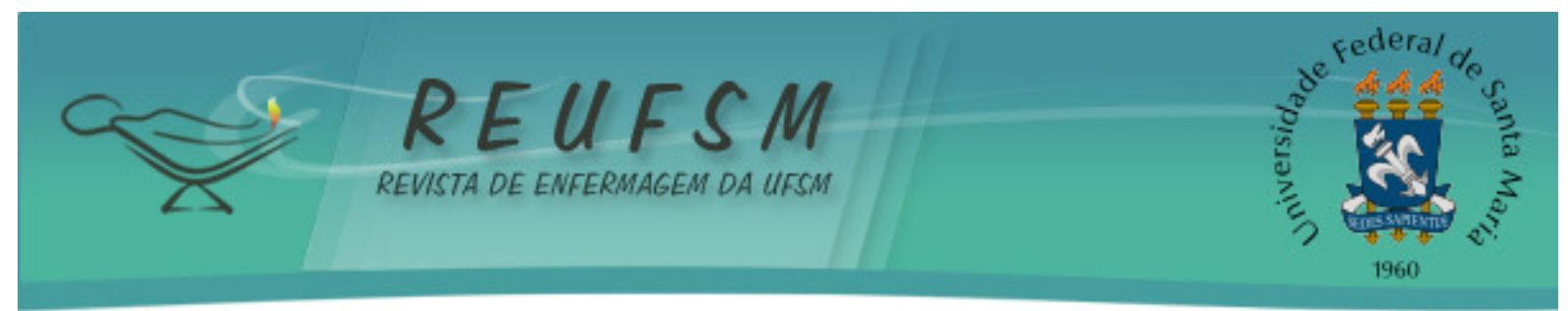

auxílio fornecido pelas mães durante o processo de amamentação, o qual pode ter representado um fator de adesão à amamentação.

Somado a isso, a enfermeira também foi sinalizada pelas mulheres como uma fonte de informação. Salienta-se a importância de que este profissional esteja imerso na realidade materna, orientando e auxiliando a mulher no que concerne à amamentação e sua prática. ${ }^{17}$ Assim, a enfermeira pode conhecer o cotidiano de vida da mulher, bem como a influência cultural, já que o ato de amamentar envolve crenças, mitos e, por vezes, vivências não satisfatórias arraigadas e repassadas no sistema cultural. ${ }^{14}$

É preciso ainda considerar, conforme apontado por um estudo, ${ }^{18}$ que, assim como os familiares, o profissional de saúde também pode influenciar na decisão da adolescente em amamentar. Quando a mulher é acolhida, assistida com respeito e the é fornecido o suporte adequado, isto pode contribuir para a diminuição do desmame precoce.

Ao considerar as influências dos familiares e dos profissionais de saúde na decisão da mulher durante a adolescência, em amamentar, sob o aspecto cultural, a amamentação pode desencadear o apoio ou a rejeição. Logo, cada mulher possui diferentes experiências e estas se mesclam também as interferências da família, do companheiro, o qual pode influenciar de acordo com o conhecimento sobre a importância da amamentação e de outros membros da comunidade em que vive, assim como dos profissionais de saúde. ${ }^{19}$

A influência cultural da mãe da adolescente também emergiu como um aspecto relevante na vivência da amamentação, capaz de determinar positivamente a sua decisão em amamentar. Ademais, pondera-se que as orientações fornecidas pela mãe foram recebidas com respeito e credibilidade pelas adolescentes, pois estavam balizadas em um processo acumulativo de saberes oriundos de vivências prévias, de acordo com 0 depoimento:

a única coisa que eu sabia era que eu tinha que dar "mamá" para ele. Era o que a minha mãe dizia, porque ela fez assim comigo e os meus irmãos. Então, eu acreditei nela, né? Ela dizia que fazia bem para a criança, igual ao que a enfermeira tinha falado no posto sobre os benefícios do meu leite para o bebê. (M4)

O prestígio atribuído pela adolescente a sua mãe resulta da habilidade que esta possui ao lidar com uma prática que, para a entrevistada, ainda precisava ser aprendida. Assim, a mãe experiente repassa seus costumes e práticas para a filha, acreditando que estes são benéficos para o neto. A filha valoriza estas orientações, pois reconhece que são permeadas por valores enraizados e culturalmente aceitos no seu contexto social, além de já terem sido comprovados em vivências prévias.

Ainda, sinaliza-se a importância da orientação sobre os benefícios da amamentação para a mulher durante a adolescência, pois ao confrontar os saberes fornecidos pela mãe com aqueles ofertados no serviço de saúde, ela não identificou divergências, o que foi fundamental para a adesão e a continuidade da amamentação. Dessa forma, evidencia-se a necessidade de entrosamento entre os profissionais de saúde e os familiares, a fim de promover estratégias de promoção e manutenção da amamentação. ${ }^{20}$

Além disso, é importante destacar a presença da avó materna durante o processo de amamentação. Tradicionalmente ela é considerada uma referência, pois já constituiu uma família e vivenciou esta prática, o que faz com que ela seja percebida como a fonte mais importante de informações, neste período. ${ }^{17,21}$

Cabe mencionar que, além da amamentação ser motivada pelos benefícios, como a nutrição natural do bebê, economia no orçamento e diminuição da mortalidade infantil, também, é incitada pelo valor atribuído pela mulher adolescente a esta prática. Destaca- 


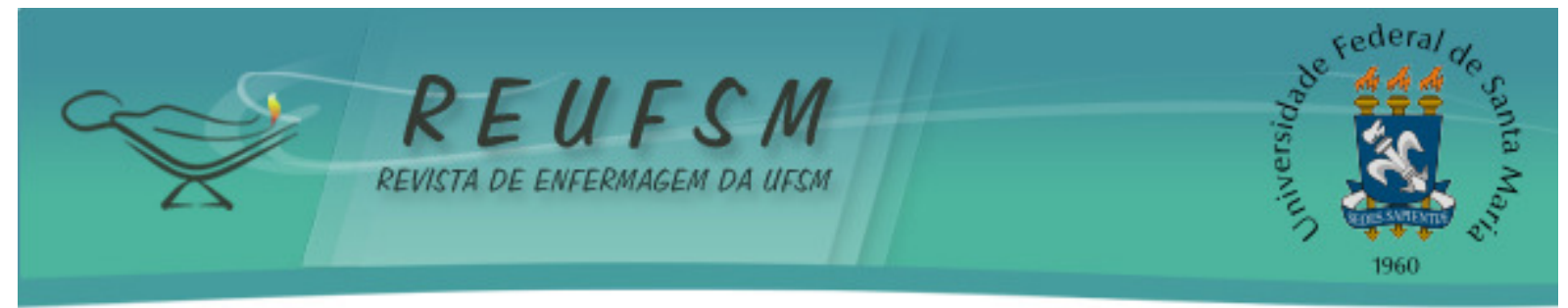

se, ainda, que este é culturalmente transmitido entre as gerações, como se pode verificar nas falas abaixo.

Doer, dói. Às vezes, sangra, mas tem que saber que tem que dar para o nenê e é isso aí. Às vezes, a gente chora dando "mamá", porque sangra e fica em carne viva, mas a gente tem que seguir. $E$ a saliva do bebê que vai ajudar a cicatrizar, o leite a saliva, tudo é remédio. (M3)

Amamentar é uma experiência única, porque ver ela ali dependendo de ti, né? Eu amamentei ela sem complemento, né? Dei só o leite até os seis meses e sinto em não ter amamentado mais. Não é falta de vínculo, mas tanto para mim quanto para ela era bom, porque quando eu parei de amamentar, ela teve várias infecções por causa da imunidade, né? [...] Eu sei que com o leite, a gente acaba passando nossa imunidade para eles, né? (M4)

Parece que amamentar dá mais proximidade, o peito pra mim, foi a melhor coisa que eu fiz para ele, e não tem discussão quanto a isso. (M6)

Assim, percebe-se que os achados desta pesquisa assemelham-se aos de outros estudos, ${ }^{2,17}$ em que a decisão de amamentar pautou-se na possibilidade da mãe fornecer o melhor para o bebê, desvelando uma preocupação com o bem-estar e a saúde da criança. Em estudo desenvolvido com 80 puérperas adolescentes, em uma maternidade de baixo risco de Ribeirão Preto, São Paulo, ${ }^{2}$ as entrevistadas se revelaram comprometidas com a amamentação e buscavam desenvolvê-la conforme as orientações que haviam recebido dos profissionais de saúde.

Já em outra pesquisa, ${ }^{3}$ as adolescentes entrevistadas revelaram a ausência de incentivo e apoio familiar para a manutenção da amamentação. Nos contextos familiares de algumas destas adolescentes, esta prática era considerada como desnecessária e/ou insuficiente para o adequado desenvolvimento da criança.

Além disso, o valor atribuído à amamentação pelas participantes se relacionou com a possibilidade de maior proximidade com o filho. Este achado também foi identificado em outro estudo desenvolvido com adolescentes, ${ }^{18}$ em que estas destacaram que a amamentação permite estabelecer uma relação de afeto com o bebê.

Ao aderir à amamentação, a mulher revela mais do que sua decisão, ela expressa sua cultura, o contexto histórico vivido, suas motivações, vivências e saberes, as ponderações acerca de suas experiências prévias e das vivências de familiares e amigas. Assim, desvela as influências dos meios de comunicação, os conhecimentos científicos de cada época, entre outros aspectos. ${ }^{17,19}$

Em relação a isso, os motivos que levam as mulheres a amamentarem na adolescência podem estar ligados à cultura, ao estilo de vida e à influência da sociedade. Dente estes, destaca-se a cultura como sendo capaz de direcionar o comportamento destas mulheres em relação à amamentação. ${ }^{8}$ Ao mesmo tempo, salienta-se que a decisão da mulher em amamentar seu filho está interligada a sua história de vida e aos aspectos emocionais, familiares, sociais, culturais e econômicos. ${ }^{20}$

Assim, compreende-se que estes aspectos são fundamentais e precisam ser compreendidos pelo profissional de saúde que assiste a mulher nessa fase. ${ }^{22}$ Entende-se que considerando esses aspectos e também as características típicas da fase da adolescência, o profissional de saúde pode qualificar as ações voltadas ao processo da amamentação. 


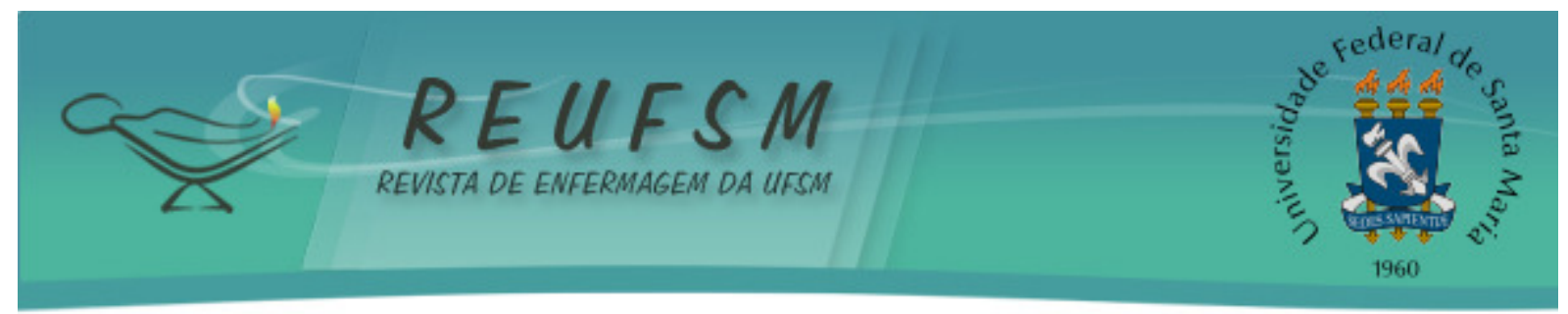

CONCLUSÃO

Cada mulher adolescente atribui à amamentação significados atrelados a sua cultura. Por constituir um ser predominantemente cultural, o comportamento da mulher frente à amamentação não é biologicamente determinado. Sendo assim, sua decisão em amamentar depende de um processo de aprendizado construído e repassado no meio cultural, em que foi socializada.

Ao profissional de saúde, que assiste à mulher em período de amamentação, cabe valorizar estes significados, assim como os padrões, os valores e o seu modo de vida. Neste sentido, é fundamental respeitar as decisões e compreendê-las como um comportamento que, possivelmente, é influenciado pelo sistema cultural.

Pondera-se que este estudo permitiu identificar limitações na área da saúde da mulher adolescente, revelando a necessidade de ações específicas a esse público, especialmente durante o período gravídico-puerperal. Considera-se que este estudo poderá estimular reflexões e discussões dentro dos espaços acadêmicos e profissionais, por meio de disciplinas ou atividades de formação, acerca de estratégias direcionadas e diferenciadas para as mulheres adolescentes.

Ainda é preciso destacar que este estudo considerou as vivências das participantes a partir de uma perspectiva cultural, ultrapassando a ótica biológica identificada na maior parte dos estudos encontrados na literatura. Diante dessas considerações, vale ressaltar que este estudo foi realizado com mulheres de uma mesma região demográfica e com cultura semelhante, o que pode configurar uma limitação do estudo.

Sugere-se, assim, que sejam realizados outros estudos em regiões diferentes, buscando conhecer e compreender outros contextos e culturas de mulheres adolescentes sobre a amamentação, uma vez que cada sistema cultural pode apresentar um determinado padrão para esta prática.

\section{REFERÊNCIAS}

1. Ministério da Saúde (BR). Aleitamento materno, distribuição de leites e fórmulas infantis em estabelecimentos de saúde e a legislação. Brasília (DF): Ministério da Saúde; 2012.

2. Camarotti CM, Nakano AMS, Pereira CR, Medeiros CP, Monteiro JCS. Perfil da prática da amamentação em grupo de mães adolescentes. Acta paul enferm. 2011;24(1):55-60.

3. Laraia RB. Cultura: um conceito antropológico. 24a reimpr. Rio de Janeiro: Zahar, 2011.

4. Takemoto AY, Santos AL, Okubo P, Bercini LO, Marcon SS. Preparo e apoio à mãe adolescente para a prática de amamentação. Cienc Cuid Saude 2011; 10(3):444-51.

5. Maranhão TA, Gomes KRO, Nunes LB, Moura LNB. Fatores associados ao aleitamento materno exclusivo entre mães adolescentes. Cad Saúde Colet [Internet]. 2015 [acesso em 2016 maio 30];23(2):132-9. Disponível em: http://www.scielo.br/pdf/cadsc/v23n2/1414462X-cadsc-23-2-132.pdf

6. Dantas ALB, Rocha SS, Coêlho IM, Araújo RA. Vivências de mães adolescentes após o nascimento do filho. R Interd [Internet] 2013 [acesso em 2016 Abr 28]; 6(3):195-203. Disponível em:

http: / / revistainterdisciplinar.uninovafapi.edu.br/index.php/revinter/article/view/12

7. Ministério da Saúde (BR). Política nacional de atenção integral à saúde das mulheres: princípio e diretrizes. 1. ed. Brasília (DF): Ministério da Saúde; 2011. 


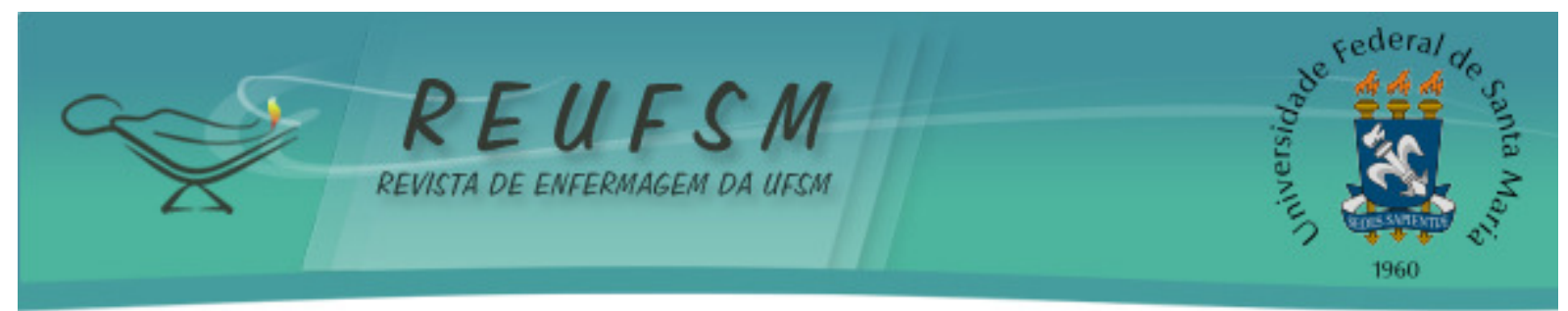

8. Geertz C. A interpretação das culturas. Rio de Janeiro: Livros Técnicos e Científicos; 1989.

9. Antonini FO, Boehs AE, Lenardt MH, Budó MLD, Monticelli M. Enfermagem e cultura: características das teses e dissertações produzidas na pós-graduação da enfermagem brasileira. Rev Enferm UFSM. [Internet] 2014 [acesso em 2015 Ago 25]; 4(1):163-171 1. Disponível em: http://cascavel.ufsm.br/revistas/ojs2.2.2/index.php/reufsm/article/view/9724/pdf

10. Fontanella BJB, Luchesi BM, Saidel MGB, Ricas J, Turato ER, Melo DG. Amostragem em pesquisas qualitativas: proposta de procedimentos para constatar saturação teórica. Cad saúde pública. [Internet] 2011 [acesso em 2014 Abr 29];27(2):389-94. Disponível em: http://www.scielo.br/pdf/csp/v27n2/20.pdf

11. Minayo MCS. O desafio do conhecimento: pesquisa qualitativa em saúde. $12^{\mathrm{a}}$ ed. São Paulo: Hucitec-Abrasco; 2013.

12. Rivemales MC, Azevedo ACC, Bastos PL. Revisão sistemática da produção científica da enfermagem sobre o desmame precoce. Rev enferm UERJ. 2010;18(1):132-7.

13. Torres LEAS, Sales JRP, Melo MCP, Mendes RNC, Mistura C. Influências sociais no processo do aleitar: percepções das mães. Revista espaço para a saúde. [Internet] 2014 [acesso em 2014 Out 23]; 15(1):25-36. Disponível em: http://www.uel.br/revistas/uel/index.php/espacoparasaude/article/view/17381

14. Henry BA, Nicolau AIO, Américo CF, Ximenes LB, Bernheim RG, Oriá MOB. Fatores socioculturais que influenciam a prática da amamentação entre mulheres de baixa renda em fortaleza, Ceará, Brasil: uma perspectiva a partir do modelo do sol nascente de Leininger. Enferm glob. [Internet] 2010 [acesso em 2014 Set 02];19(2). Disponível em: http://scielo.isciii.es/pdf/eg/n19/pt_clinica4.pdf

15. Mazza VA, Silva DI, Gonçalves JB, Mantovani MF, Tararthuch RZP. Representações sociais da nutrizes adolescentes sobre a amamentação. J res fundam care online [Internet] 2015 [acesso em 2016 Abr 28]; 7(2):2405-2414. Disponível em: http://www.seer.unirio.br/index.php/cuidadofundamental/article/view/3994/pdf_1597

16. Alves VH, Rodrigues DP, Cabrita BAC, Vieira BDG, Branco MBLR, Sá AMP. Amamentação prática avaliativa como saber fazer: um estudo descritivo. Online braz $\mathrm{j}$ nurs [Internet]. 2013 [acesso em 2014 Set 21]; 12(4):902-10. Disponível em: http://www.objnursing.uff.br/index.php/nursing/article/view/4154

17. Marques ES, Cotta RMM, Magalhães KA, Sant'Ana LFR, Gomes AP, Batista RS. A influência da rede social da nutriz no aleitamento materno: o papel estratégico dos familiares e dos profissionais de saúde. Ciênc saúde coletiva. [Internet] 2010 [acesso em 2015 Ago 24];15(1):1391-400. Disponível em: http://www.scielo.br/pdf/csc/v15s1/049.pdf

18. Spindola T, Oliveira ACFC, Cavalcanti RL, Fonte VRF. Amamentação na adolescência: história de vida de mães primíparas. J res fundam care online [Internet] 2014 [acesso em 2016 Abr 28]; 6(1): 414-24. Disponível em: http://www.seer.unirio.br/index.php/cuidadofundamental/article/view/2965/pdf_1094

19. Junges CF, Ressel LB, Budó MLD, Padoin SMM, Hoffmann IC, Sehnem GD. Percepções de puérperas quanto aos fatores que influenciam o aleitamento materno. Rev gaúch enferm. [Internet] 2010 [acesso em 2015 Ago 24];31(2):343-50. Disponível em: http://www.scielo.br/pdf/rgenf/v31n2/20.pdf 


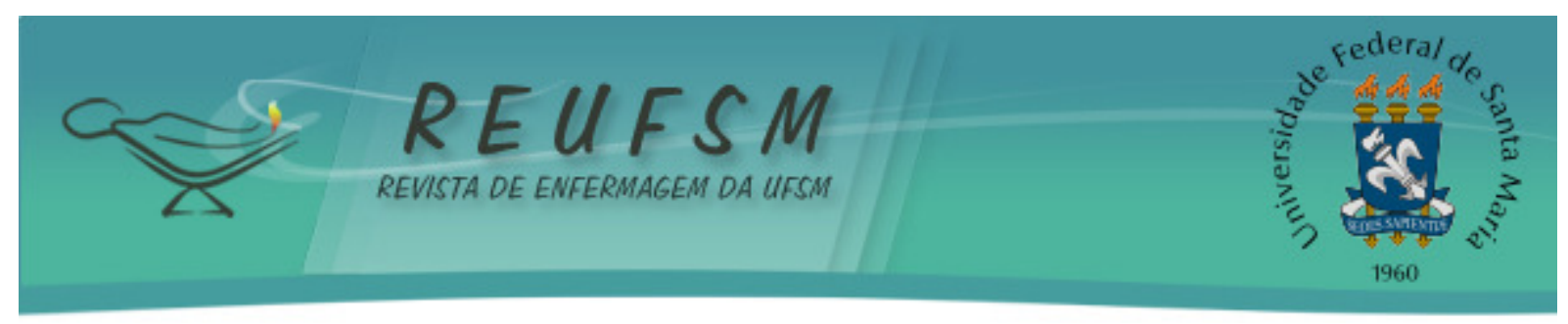

20. Zanin LC, Schacker LC. Avós maternas: incentivadoras da amamentação? Rev Conhecimento Online [Internet]. 2010 [acesso em 2015 Ago 11];1:1-13. Disponível em: http://www.feevale.br/site/files/documentos/pdf/35211.pdf

21. Teixeira MA, Nitschke RG, Silva LWS. A prática da amamentação no cotidiano familiar um contexto integeracional: influência das mulheres-avós. Rev Kairós. [Internet] 2011 [acesso em 2015 Ago 13];14(3):205-21. Disponível em: http://revistas.pucsp.br/index.php/kairos/article/view/6501/4713

22. Wilhelm LA, Demori CC, Alves CN, Barreto CN, Cremonese L, Ressel LB. A vivência da amamentação na ótica de mulheres: contribuições para a enfermagem. Rev Enferm UFSM. [Internet] 2015 [acesso em 2015 Abr 12];5(1):160-8. Disponível em: http://cascavel.ufsm.br/revistas/ojs-2.2.2/index.php/reufsm/article/view/15409/pdf

Data de recebimento: $26 / 08 / 2015$

Data de aceite: 08/06/2016

Contato do autor responsável: Luiza Cremonese

Endereço postal: Rua Francisco Manoel, 27, apto 402, centro. Santa Maria/RS. CEP 97915-260.

E-mail: lu_cremonese@hotmail.com 